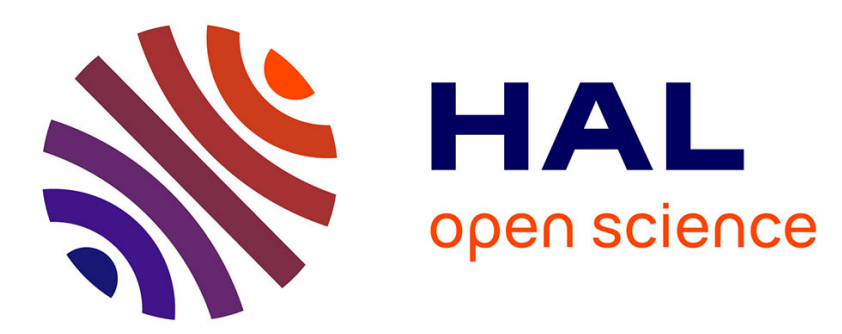

\title{
Thermal Hysteresis of Photoinduced Magnetic Effect in Yttrium Iron Garnet
}

\author{
K. Hisatake, I. Matsubara, K. Maeda, H. Yasuoka, H. Mazaki, H. Shinohara, \\ K. Uematsu
}

\section{- To cite this version:}

K. Hisatake, I. Matsubara, K. Maeda, H. Yasuoka, H. Mazaki, et al.. Thermal Hysteresis of Photoinduced Magnetic Effect in Yttrium Iron Garnet. Journal de Physique IV Proceedings, 1997, 07 (C1), pp.C1-293-C1-294. 10.1051/jp4:19971116 . jpa-00254756

\section{HAL Id: jpa-00254756 https://hal.science/jpa-00254756}

Submitted on 1 Jan 1997

HAL is a multi-disciplinary open access archive for the deposit and dissemination of scientific research documents, whether they are published or not. The documents may come from teaching and research institutions in France or abroad, or from public or private research centers.
L'archive ouverte pluridisciplinaire HAL, est destinée au dépôt et à la diffusion de documents scientifiques de niveau recherche, publiés ou non, émanant des établissements d'enseignement et de recherche français ou étrangers, des laboratoires publics ou privés. 


\title{
Thermal Hysteresis of Photoinduced Magnetic Effect in Yttrium Iron Garnet
}

\author{
K. Hisatake, I. Matsubara, K. Maeda, H. Yasuoka*, H. Mazaki*, H. Shinohara** and K. Uematsu*** \\ Kanagawa Dental College, Yokosuka, Kanagawa 238, Japan \\ * The National Defence Academy, Yokosuka, Kanagawa 239, Japan \\ ** Magnetic Materials Research Laboratory, Hitachi Metals, Ltd., Kumagaya, Saitama 350, Japan \\ *** Advanced Research Center for Science and Engineering, Waseda University, Tokyo 169, Japan
}

\begin{abstract}
In single crystals of yttrium iron garnet irradiated with laser (the most effective wavelength is $700 \mathrm{~nm}$ ) or white fight at $77 \mathrm{~K}$, a remarkable change of the temperature dependence of complex permeabilities $\mu^{\prime \prime}$ and $\mu^{\prime \prime}$ is observed, which is peculiar to photoinduced magnetic effect. Simultaneously, conspicuous double peaks of DA around $125 \mathrm{~K}$ and $200 \mathrm{~K}$ below room temperature were found to be induced by light-irradiation, with correlative onset of the irreversible decrease of permeability insensitive to demagnetization at low temperature. In order to explain these observations, we propose a new model.
\end{abstract}

\section{INTRODUCTION}

Photoinduced magnetic effects in Si-doped yttrium iron gamet (YTG:Si) has attracted the attention of researchers since Teal et al. [1] found for the first time one of these effects, so called the I-effect These effects can be divided into. the I-effect (vectorial) and the II-effect (scalar) in dependence on whether is dominant or not the polarization state of light for the observation. The origin of I-ffect was explained as a redistribution of uniaxial anisotropy of $\mathrm{Fe}^{2+}$ along one of the four cubic directions of octahedral sites, while the II-ffect (Enz-type) was attributed to the different behaviors of $\mathrm{Fe}^{2+}$ close to and far from $\mathrm{Si}^{4+}$ ions, in the demagnetized state [2]. Disaccommodation (DA) in the dark which is often observed is, phenomenologically, similar to the II-effect[3]. DA is, however,so far considered as essentially different from the II-effect, since the former is sensitive but the latter:is insensitive to demagnetization. In this report, we observed a thermal hysteresis and the phenomenon of DA can be produced by white light irradiation in the high purity crystals of YIG [4] indicating of photoinduced formation and relaxation of a potential barrier for photoexcited electron to return to an original state.

\section{EXPERIMENTAL}

These samples of YIG are very pure, with neither $\mathrm{Si}$ nor $\mathrm{Ca}$ incorporated except for intentional dopants (Ga $0.0625 \mathrm{~mol}$ or $\mathrm{Ca}$ $0.001 \mathrm{~mol}$ ). In all samples, however, a considerable oxygen vacancy is incorporated of the order of $0.1 \mathrm{~mol} \%$ estimated from spectroscopic method. Source of irradiating the samples was a xenon lamp, since no conspicuous differences among the many kinds of light sources such as laser light(650nm-laser is the most effective in the range among $1520 \mathrm{~nm}-500 \mathrm{~nm}$ ), mercury light, X-ray and or gamma-ray[4] employed in this experiment.

\section{RESULTS AND DISCUSSION}

The permeability of YIG which is decreased by irradiation at low temperatiure returns to the state prior to irradiation, when the sample is once brought back to room temperature[2]. In order to examine the more detail of the behavior, the warming process was stopped at several temperatures termed as turning temperature Tr below room temperature and then the sample was returned to $77 \mathrm{~K}$. Without irradiation, the sample was again warmed to room temperature. The temperature dependence of complex permeabilities $\mu^{\prime}$ and $\mu^{\prime \prime}$ of the samples after white light irradiation was found to show a thermal hysteresis or 
the different permeabilities at the 1 st run and the 2nd nun as shown in fig. 1 . Both of $\mu^{\prime}$ and $\mu^{\prime \prime}$ at the 2nd run appear featureless curve as a function of temperature. The concaves of permeabilities versus temperature curves $(125 \mathrm{~K}$ and $200 \mathrm{~K})$ were ascribed to photoinduced DA which was confirmed by using the automatic DA tester. In several samples, an additional DA peak independent of irradiation is observed around room temperature, the reason of which may be ascribed to oxygen vacancy with double electrons trapped [5]. These results are interpreted within the context of configuration coordinate(CC) diagrams with large lattice relaxations[6]. In this case the photoexcitation energy is larger than leV while the thermal energy for recovery process is less than $0.1 \mathrm{eV}$. The basic concept of our explanation is as follows. Cooled in the dark, oxygen vacancies or deep donors capture the double electrons and so called F-centers are formed. Pinning centers for domain walls are created due to lattice distortion, when the trapped electrons are photoexcited from the deep levels to the conduction band.
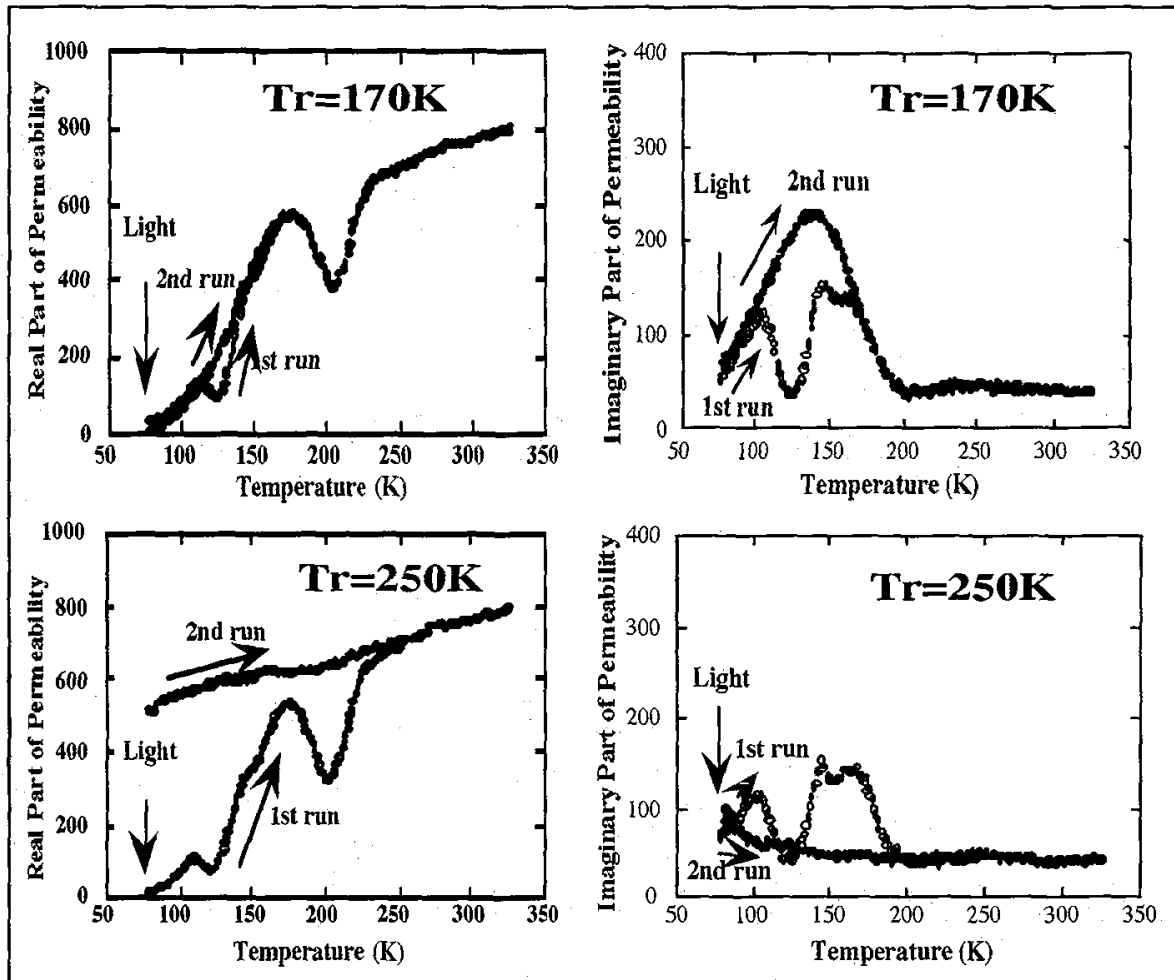

Fig.1 Temperature dependence of complex permeabilities $\mu^{\prime}$ and $\mu^{\prime \prime}$ of the samples after white light irradiation (measuring frequency and field , $1 \mathrm{kHz}$ and $1 \mathrm{mOe}$, raising temperature rate $; 0.5 \mathrm{~K} / \mathrm{min}$ ).

\section{References}

[1] Teal R.W.and Temple D.W.,Phys.Rev.Lett. 19(1967)1038-1039.

[2] Holtwijk T.,Lems W., Verhulst A.G.H., and Enz U., IEEE Trans. on MAG-6(1970)853-857.

[3] Torres L.,Zazo M.,Iniguez J.,Francisco C.,Munoz J. M., and Hernandez P.,Appl.Phys.Lett.68(1996)564-565.

[4] Hisatake K.,Matsubara I. ,Maeda K., and Lyakhimets S.N., IEEE Trans.on MAG-30(1994)975-977.

[5] Hisatake K.,Matsubara I. ,Maeda K., and Uematsu K.,J.Mag.Mag.Mat.112(1992)385-387.

[6] Hisatake K.,Matsubara I. ,Maeda K., and Lyakhimets S.N., Jpn . J. Appl. Phys. Suppl. 32-3(1994)348-349. 